Article

\title{
The Natural Product Citral Can Cause Significant Damage to the Hyphal Cell Walls of Magnaporthe grisea
}

\author{
Rong-Yu Li ${ }^{1,2,3}$, Xiao-Mao Wu ${ }^{1,2}$, Xian-Hui Yin ${ }^{1,2}$, Jing-Nan Liang ${ }^{4}$ and Ming $\mathrm{Li}^{1,2,3, *}$ \\ 1 Institute of Crop Protection, Guizhou University, Guiyang 550025, China \\ 2 The Provincial Key Laboratory for Agricultural Pest Management in Mountainous Region, \\ Guizhou University, Guiyang 550025, China \\ 3 Key Laboratory of Green Pesticide and Agricultural Bioengineering, Ministry of Education of \\ China, Research and Development Center for Fine Chemicals, Guizhou University, \\ Guiyang 550025, China \\ 4 Instrument Center of Institute of Microbiology Chinese Academy of Sciences, Institute of \\ Microbiology, Chinese Academy of Science, Beijing 100101, China \\ * Author to whom correspondence should be addressed; E-Mail: 1m21959@163.com; \\ Tel./Fax: +86-0851-829-1585.
}

Received: 19 June 2014; in revised form: 1 July 2014 / Accepted: 10 July 2014 /

Published: 15 July 2014

Abstract: In order to find a natural alternative to the synthetic fungicides currently used against the devastating rice blast fungus, Magnaporthe grisea, this study explored the antifungal potential of citral and its mechanism of action. It was found that citral not only inhibited hyphal growth of M. grisea, but also caused a series of marked hyphal morphological and structural alterations. Specifically, citral was tested for antifungal activity against $M$. grisea in vitro and was found to significantly inhibit colony development and mycelial growth with $\mathrm{IC}_{50}$ and $\mathrm{IC}_{90}$ values of 40.71 and $203.75 \mu \mathrm{g} / \mathrm{mL}$, respectively. Furthermore, citral reduced spore germination and germ tube length in a concentration-dependent manner. Following exposure to citral, the hyphal cell surface became wrinkled with folds and cell breakage that were observed under scanning electron microscopy (SEM). There was damage to hyphal cell walls and membrane structures, loss of villous-like material outside of the cell wall, thinning of the cell wall, and discontinuities formed in the cell membrane following treatment based on transmission electron microscopy (TEM). This increase in chitinase activity both supports the morphological changes seen in the hyphae, and also suggests a mechanism of action. In conclusion, citral 
has strong antifungal properties, and treatment with this compound is capable of causing significant damage to the hyphal cell walls of $M$. grisea.

Keywords: Magnaporthe grisea; antifungal activity; natural product citral; electron microscopy; chitinases

\section{Introduction}

Rice (Oryza sativa) is one of the most important food crops in the world, according to the International Rice Research Institute database, and is cultivated worldwide on over 153 million hectares [1]. However, rice blast disease (RBD), caused by the fungus Magnaporthe grisea, is a significant and recurring problem in China and other rice-growing regions $[2,3]$. The fungus is a filamentous ascomycete with a broad host range and worldwide distribution. It is one of the most devastating of all cereal diseases due to the critically decrease in both rice yield and quality [1,4], and it causes between $10 \%-30 \%$ of the annual rice harvest losses [2,5].

One common solution to controlling these pathogenic fungi is the use of synthetic chemical fungicides, however, their use often results in other problems. These problems include threatening human health and the environment by supporting the emergence of resistant pathogens $[3,6-8]$, and by leaving pesticide deposits on food [6]. Therefore, naturally occurring plant products are important sources of antifungal compounds with low toxicity to mammals and safe to the environment which may serve as substitutes for synthetically produced fungicides $[9,10]$. Compared to synthetic chemical fungicides that show insecticidal activity, botanical fungicides are recognized to have relatively low or little toxicity [11], but they can play an important role in reducing environmental pollution in agricultural ecosystems [12].

A key component of the essential oils from Litsea cubeba is citral (3,7-dimethyl-2-7-octadienal), which is extracted from the L. cubeba fruits. Citral is an acyclic $\alpha, \beta$-unsaturated monoterpene aldehyde, and an isoprenoid compound made up of the isomers geranial and neral [13-15]. Because of its high bioreactivity, including antimicrobial (human pathogenic fungi and bacterium) and insecticidal properties, citral has been the focus of attention of numerous researchers [16-18]. However, the application of natural compound citral against fungal diseases for agriculture is very minor, like other plants extracts which are effective, selective, biodegradable, and less toxic to the environment. In addition, there is little study related to the investigation of compounds which are responsible for the bioactivities of citral, and its exact mechanism of antimicrobial action. Despite the previous research on citral, its effect on M. grisea and corresponding mechanism of action have not yet been elucidated. Therefore, the goal of the present study was to investigate the antifungal activity of citral isolated from L. cubeba oils on M. grisea, and to describe the effects on the gross morphology and ultrastructure of M. grisea hyphae by scanning electron microscopy (SEM) and transmission electron microscopy (TEM). 


\section{Results and Discussion}

\subsection{Effects of Citral on Fungal Hyphal Growth}

The effect of citral on mycelial growth of $M$. grisea was determined for a range of citral concentrations as shown in Figure 1. It was found that supplementing with citral significantly reduced M.grisea colony development on potato dextrose agar (PDA) 6 days after inoculating. Specifically, a citral concentration of $200 \mu \mathrm{g} / \mathrm{mL}$ inhibited growth to $0.25 \mathrm{~cm}$, and $12.50 \mu \mathrm{g} / \mathrm{mL}$ up to $4.26 \mathrm{~cm}$. Moreover, the highest citral concentration tested, $200 \mu \mathrm{g} / \mathrm{mL}$, resulted in complete $(100 \%)$ inhibition of fungal colony development at 2-5 days, after which mycelial growth recommenced. Following a 7 days inoculation, the antifungal activity of citral was $21.76 \%$ at $12.50 \mu \mathrm{g} / \mathrm{mL}$ and $91.93 \%$ at $200 \mu \mathrm{g} / \mathrm{mL}$. Furthermore, citral significantly inhibited the mycelial growth of $M$. grisea in a concentrationdependent manner with $\mathrm{IC}_{50}$ and $\mathrm{IC}_{90}$ values of 40.71 and $203.75 \mu \mathrm{g} / \mathrm{mL}$, respectively. A previous study reported that citral at concentrations of 50 and $100 \mu \mathrm{g} / \mathrm{mL}$ can decrease Trichophyton mentagrophytes growth in PDA by $8.5 \%$ and $100 \%$, respectively [19]. These results also agree with those of Saddiq and Khayyat [17] and Wuryatmo et al. [20], who reported on the strong antifungal activity of citral.

Figure 1. Effect of citral on M. grisea mycelial growth.

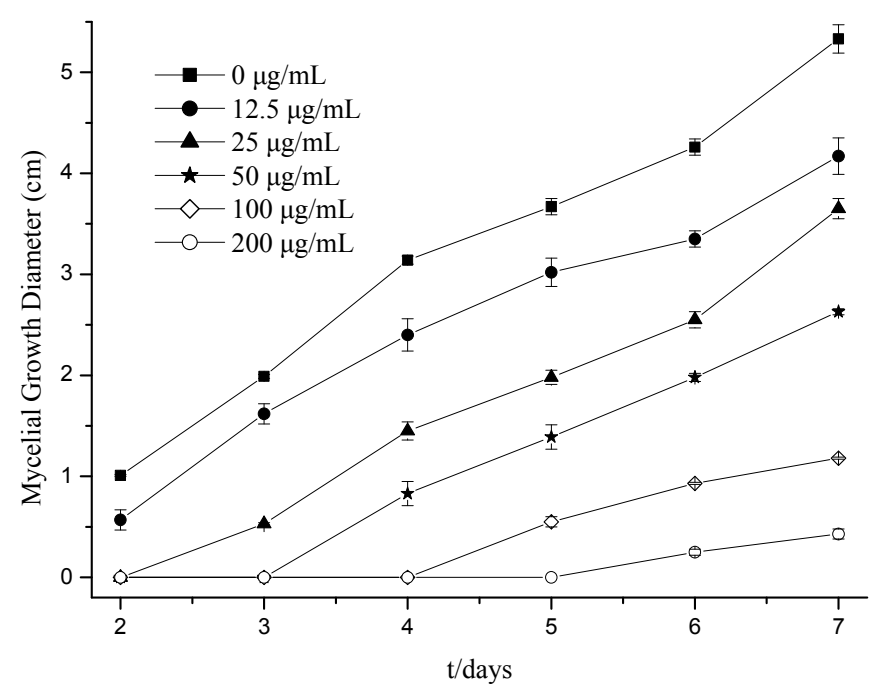

\subsection{Effects of Citral on Germination of Fungal Spores}

The effect of citral on $M$. grisea conidia germination and germ tube elongation were measured and the results are listed in Table 1. It was found that spore germination was significantly inhibited by citral in a concentration-dependent manner, and a similar trend was observed for mycelial growth. When treating with $200 \mu \mathrm{g} / \mathrm{mL}$ citral, there was a 5.20\% inhibition of spore germination. Overall, the $\mathrm{IC}_{50}$ of citral was $38.81 \mu \mathrm{g} / \mathrm{mL}$. Spore germination increased as the citral concentration was reduced, which resulted in an increase in $M$. grisea germ tube length. As the citral concentration went from $200 \mu \mathrm{g} / \mathrm{mL}$ to $12.50 \mu \mathrm{g} / \mathrm{mL}$, the germ tube length of $M$. grisea went from $12.67 \mu \mathrm{m}$ to $175.67 \mu \mathrm{m}$, respectively. Conidia germination and appressorium formation were also suppressed by citral treatment of $\geq 400 \mu \mathrm{g} / \mathrm{mL}$. 
These results confirm previously published work, such as that by Silva et al. [16], and Ganjewala et al. [21], Daferera et al. [22], concerning the efficacy of citral for inhibition of pathogenic fungi growth.

Table 1. Effect of citral on the spore germination and germ tube length of M. grisea.

\begin{tabular}{ccc}
\hline Citral Treatment $(\boldsymbol{\mu g} / \mathbf{m L})$ & Spore Germination Rate (\%) & Germ Tube Length $(\boldsymbol{\mu m})$ \\
\hline 0 & $100.00 \mathrm{a}$ & $175.67 \mathrm{a}$ \\
12.5 & $89.66 \mathrm{~b}$ & $123.78 \mathrm{~b}$ \\
25 & $70.90 \mathrm{c}$ & $91.11 \mathrm{c}$ \\
50 & $34.47 \mathrm{~d}$ & $54.44 \mathrm{~d}$ \\
100 & $14.40 \mathrm{e}$ & $30.11 \mathrm{e}$ \\
200 & $5.20 \mathrm{f}$ & $12.67 \mathrm{f}$ \\
400 & $0.00 \mathrm{j}$ & $0.00 \mathrm{j}$ \\
\hline
\end{tabular}

Values represent means of measurements for six independent plates per treatment. In each column, the values followed by the same letter do not differ significantly for $p<0.05$.

The described inhibitory activity of citral against fungi is most likely due to citral being a member of the $\alpha, \beta$-unsaturated aldehyde class in which the carbonyl group is adjacent to the $\alpha$ and $\beta$-carbons. Because of their location on the molecule, the $\alpha$ and $\beta$-carbons are conjugated with the carbonyl group, which makes the $\alpha$-carbon positively polarized and able to react easily with nucleophiles and undergo nuclephilic attack [23]. According to Witz, the chemical nature of $\alpha, \beta$-unsaturated aldehydes, as well as some of their toxicological effects, are based on their ability to function as direct alkylating agents [24]. These alkylating agents are capable of binding covalently to cellular nucleophile groups, meaning they are capable of modifying cellular processes and have potential toxicity.

\subsection{Electron Microscope Analysis of M. grisea}

Observations made by SEM indicated that untreated $M$. grisea hyphae had a complete tubular shape and were morphologically normal (Figure 2a). After exposure to a citral concentration of $50.00 \mu \mathrm{g} / \mathrm{mL}$, the hyphae still maintained an almost normal morphology (Figure 2b). However, once the concentrations of citral were increased to $100.00,150.00$ and $200.00 \mu \mathrm{g} / \mathrm{mL}$, the hyphae displayed aberrant morphologies, including shrinkage, partial distortion and wrinkling of the surface (Figure 2). Such morphological changes were also evident in the hyphae treated with $100.00 \mu \mathrm{g} / \mathrm{mL}$ citral (Figure 2c). These distorted hyphae had a flattened appearance. Similar conclusions have also been made in previous studies by Maoz and Neeman [25], and Xiong et al. [26], who also found that hyphae morphology becomes irregular under certain treatment conditions.

TEM studies of untreated M. grisea hyphae revealed the presence of typical eukaryotic cytoplasmic components, including numerous ribosomes, mitochondria and vacuoles in the cytoplasm enclosed by an electron-transparent cell wall (Figure 3a,b). The mitochondria had well-developed cristae that projected into the matrices. On the other hand, mycelia that had been treated with citral showed ultrastructural changes in the hyphal morphology. Following exposure to $50.00 \mu \mathrm{g} / \mathrm{mL}$ citral, the cell walls of the hyphae became rough, and some vesicles containing electron dense structures appeared in the vacuoles (Figure 3c,d). When hyphae were exposed to $100.00 \mu \mathrm{g} / \mathrm{mL}$ citral, the cellular degeneration was severe, with the presence of indiscernible organelles in the cytoplasm, and cell ghosts were often found where various round shaped structures appeared. Furthermore, the cell walls 
appeared to be degraded and had an exfoliated texture (Figure 3e,f). After increasing the concentration of citral to $200.00 \mu \mathrm{g} / \mathrm{mL}$, the cytoplasm almost completely disappeared and the cell wall ruptured. There was also a remarkable increase in the number of cell ghosts (Figure 3g,h). Overall, the treated cells became abnormal and displayed cellular disorganization upon exposure to citral, suggesting that citral ruptures the cell wall, penetrates the cell membrane and interacts with cellular organelles. These phenomena that were observed agree with Arlorio et al. [27], who observed the rupture of fungal cell walls upon exposure to citral. These phenomena are likely due to the structure of citral, because the effects of solutes on cell walls might be influenced by compounds that possess a hydrophilic group and an electron acceptor group, such as an aldehyde group [25,26].

Figure 2. Scanning electron micrographs of $M$. grisea: Hyphae exposed to citral at concentrations of (a) $0 \mu \mathrm{g} / \mathrm{mL}$, (b) $50.00 \mu \mathrm{g} / \mathrm{mL}$, (c) $100.00 \mu \mathrm{g} / \mathrm{mL}$, (d) $150.00 \mu \mathrm{g} / \mathrm{mL}$, and (e) $200.00 \mu \mathrm{g} / \mathrm{mL}$. Arrows and arrowheads indicate hyphae shrinkage and partial distortion, respectively.

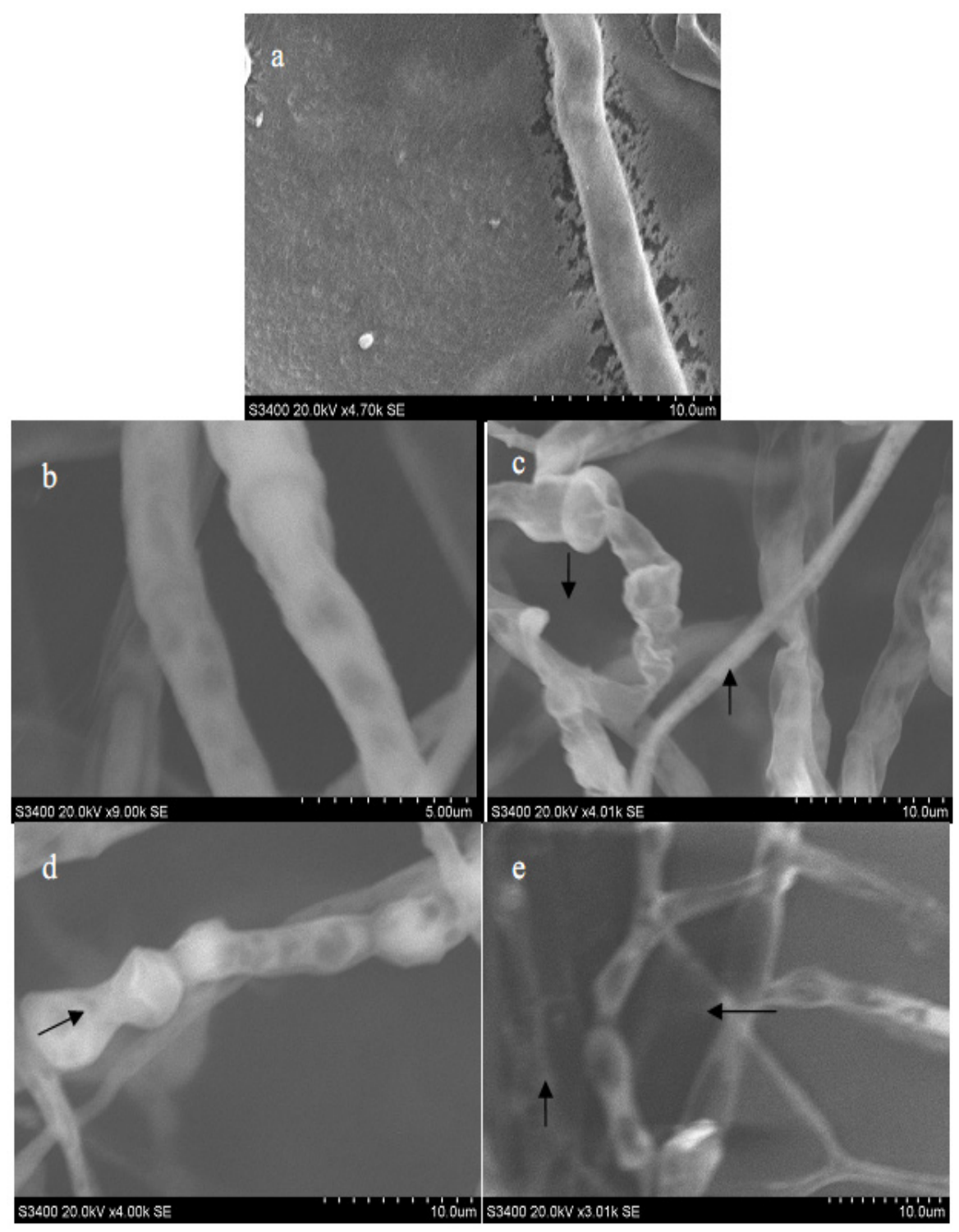


Figure 3. Transmission electron micrographs of $M$. grisea hyphae, where hyphae was exposed to agar with citral at (a, b) $0 \mu \mathrm{g} / \mathrm{mL},(\mathbf{c}, \mathbf{d}) 50.00 \mu \mathrm{g} / \mathrm{mL},(\mathbf{e}, \mathbf{f}) 100.00 \mu \mathrm{g} / \mathrm{mL}$, and (g,h) $200.00 \mu \mathrm{g} / \mathrm{mL}$. CW: Cell wall.
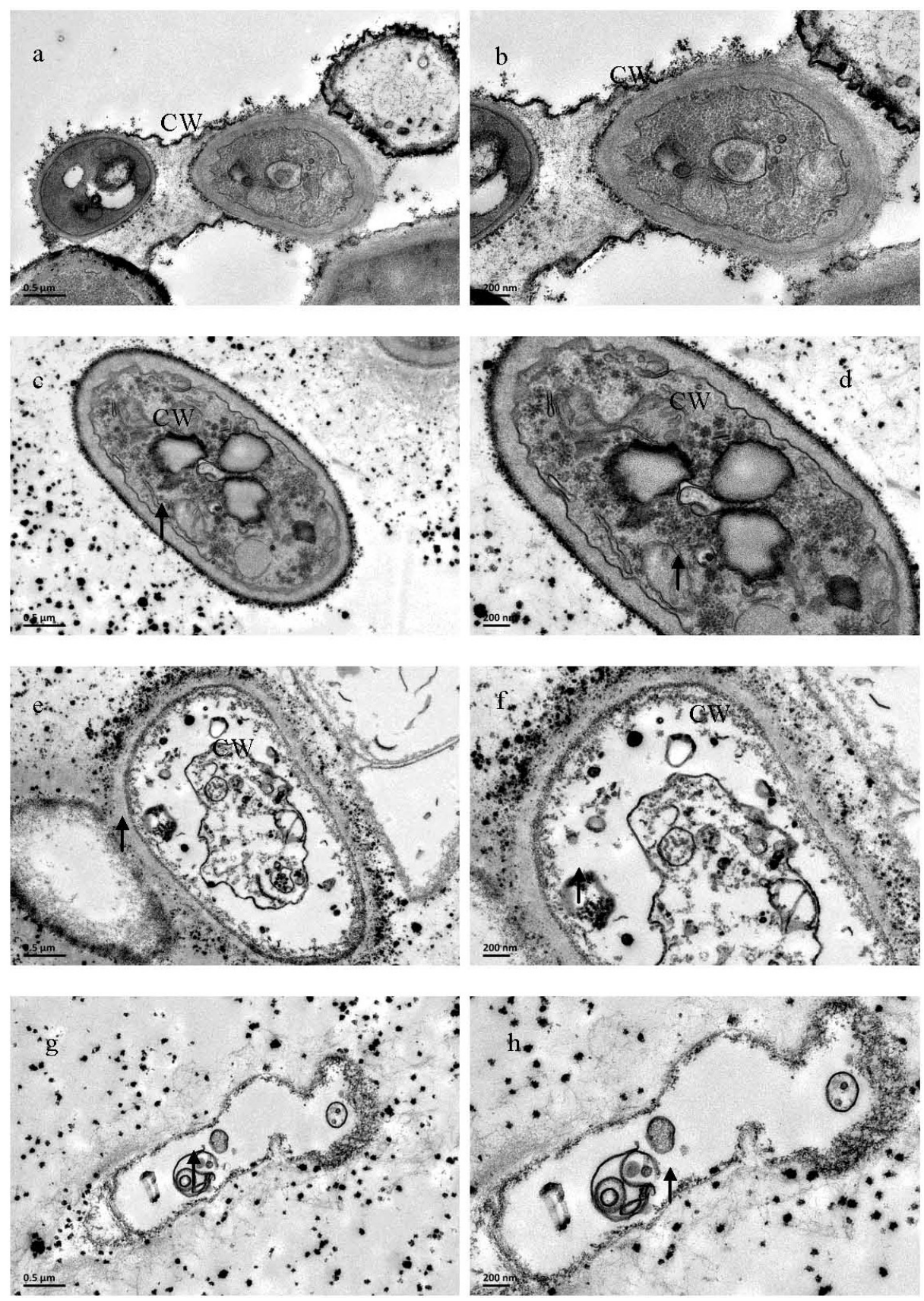

\subsection{Effect of Citral on Chitinases Activity of M. grisea}

Chitinases are digestive enzymes that break down glycosidic bonds in chitin. In fungi, chitinase has been to be shown to be involved in regulating degradation of cell walls, germination of spores, tip growth, branching of hyphae, detachment of spores, and autolysis of hyphae [28-30]. The present paper demonstrated the effect of citral on the chitinase activity of M. grisea (Figure 4). Treatment with citral significantly increased the activity of the enzyme in the sample as compared to the control. Within the first $3 \mathrm{~h}$ of citral treatment, the chitinase activity of $M$. grisea decreased, and then after $3 \mathrm{~h}$, the activity increased. Six h after the treatment, the chitinases displayed the highest level of activity at 
the highest citral concentration of $200 \mu \mathrm{g} / \mathrm{mL}$ with an activity increase of $73.52 \%$ as compared with the blank group. When treating with the concentration of $100 \mu \mathrm{g} / \mathrm{mL}$, the chitinase activity had increased $60.55 \%$ as compared with the control $9 \mathrm{~h}$ after treatment. By $24 \mathrm{~h}$ after treatment, chitinase activity was stable. Therefore, citral can significantly increase chitinase activity, and thereby cause degradation of cell walls. This results fits with the the morphological changes in the hyphae with citral treatment, and agrees with the results of Maoz and Neeman [25], Adams [30], Mauch et al. [31] Sela-Buurlage et al. [32], and Bruno and Donzelli [33], who have also observed that chitinase is involved in the regulation of cell wall degradation.

Figure 4. Effect of citral on the chitinase activity of $M$. grisea.

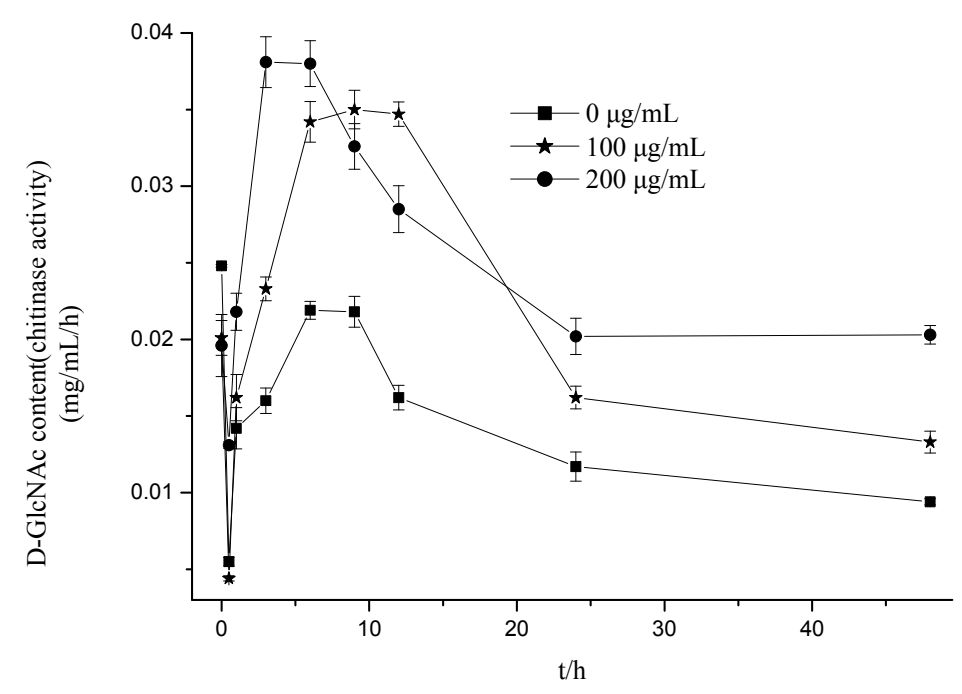

\section{Experimental Section}

\subsection{Chemicals and Samples}

M. grisea strain ZB15 was isolated from a diseased rice panicle taken from Guizhou Province in China and incubated on potato dextrose agar (PDA) plates at $28{ }^{\circ} \mathrm{C}$. A single-spore isolate was obtained and maintained at $4{ }^{\circ} \mathrm{C}$ on PDA. Citral (purity $\geq 95 \%$ ) was isolated from Litsea cubeba essential oils, dissolved in acetone to make a $1 \mathrm{mg} / \mathrm{mL}$ stock solution, and stored at $4{ }^{\circ} \mathrm{C}$. PDA or potato dextrose broth (PDB) was used for routine cultures. Rice bran medium (RBM) was prepared for conidia propagation by boiling $20.0 \mathrm{~g}$ of rice brain, adding $10.0 \mathrm{~g}$ each of sucrose and agar, and diluting to a final volume of $1 \mathrm{~L}$ with distilled water.

\subsection{Impact of Citral on Fungal Hyphal Growth}

The antifungal tests of citral was carried out for assessing the effects towards mycelial growth of $M$. grisea as described previously [34]. For determination of contact effects, citral was dispersed as an emulsion in water using dimethyl sulfoxide (DMSO) and Tween $80(0.1 \% \mathrm{v} / \mathrm{v})$ and added to PDA immediately before it was emptied into the glass Petri dishes ( $90 \mathrm{~mm}$ in diameter) at a temperature of $40-45^{\circ} \mathrm{C}$. The concentrations tested were 12.5 to $200 \mu \mathrm{g} / \mathrm{mL}$. The controls received the same quantity of DMSO and Tween 80 mixed with PDA. Then the plates were kept under UV light in the laminar 
flow chamber for solidification of the media. After solidification, a $6 \mathrm{~mm}$ diameter disc cut from the actively growing front of a 1-week old colony of the desired pathogenic fungus was then placed with the inoculum side down in the center of each treatment plate, aseptically. Treated petri dishes were then incubated at $28{ }^{\circ} \mathrm{C}$ till the fungal growth was almost complete in the control plates. All experiments were in quadruplet for each treatment against $M$. grisea. The diameters of the fungal growth were measured after 2, 3, 4, 5, 6 and 7 days. The formula for calculating the growth inhibition of fungal hyphae was as follows:

$$
\text { Inhibition }(\%)=(1-\mathrm{Dt} / \mathrm{Dc}) \times 100
$$

where Dt and Dc were the growth zone diameters in the experimental dish ( $\mathrm{mm})$ and the control dish $(\mathrm{mm})$, respectively. Concentrations of compounds that inhibited $50 \%$ of the mycelium growth ( $\mathrm{IC}_{50}$ values) were calculated by probit analysis [34].

\subsection{Impact of Citral on Fungal Spore Germination}

In order to determine the effect citral has on fungal spore germination, the following procedure was performed. PDA in Petri dishes were inoculated with mycelial plugs of $M$. grisea and incubated at $28^{\circ} \mathrm{C}$. After 14 days, conidia of $M$. grisea in each dish were harvested and air dried at room temperature. These $M$. grisea conidia were submerged in $20 \mathrm{~mL}$ of citral solutions at a concentration of $12.5,25,50$, 100,200 , and $400 \mu \mathrm{g} / \mathrm{mL}$ at $28{ }^{\circ} \mathrm{C}$ for $24 \mathrm{~h}$ or submerged in distilled water. The conidia were rinsed three times for $1 \mathrm{~min}$ each in sterile distilled water. Spore germination and morphological changes were monitored microscopically. The percentage of germinated conidia that formed appressoria was determined by direct microscopic examination of at least 100 spores per replicate [6]. The inhibition of spore germination was calculated from the experimental mean values as follows:

$$
\text { Inhibition }(\%)=100 \times(A-B) / A
$$

where $A$ and $B$ are the percentages of germinated spores in the control and test sample, respectively. The $\mathrm{IC}_{50}$ value was calculated by probit analysis.

\subsection{Morphological Study}

For morphological studies, treatments were prepared by adding different concentrations of citral in PDA to each petri dish, and then growing M. grisea on these Petri dishes at $28{ }^{\circ} \mathrm{C}$ for 10 days. Samples for SEM observation were prepared as follows: mycelia were obtained after exposure to citral and then fixed with $4 \%(\mathrm{v} / \mathrm{v})$ glutaraldehyde at $4{ }^{\circ} \mathrm{C}$ overnight. After fixing, mycelia were washed briefly with $0.1 \mathrm{~mol} / \mathrm{L}$ phosphate buffered saline ( $\mathrm{PBS}, \mathrm{pH}=7.2$ ) twice, and then dehydrated in a graded t-butanol series of $30 \%, 50 \%, 70 \%, 90 \%$ and then $100 \%$ three times for 10 min each. The dehydrated specimens were dried in a freeze drier (LGJ-10D; Beijing Fourth Ring Scientific Instrument Co., Ltd., Beijing, China), and sputter-coated with gold. Observations were carried out using a SEM (S-3400N; Hitachi, Tokyo, Japan) operated at an accelerating voltage of $20 \mathrm{kV}$. Untreated mycelia were processed alongside test samples as a control.

For TEM analysis, mycelia samples were processed as follows. The specimens were fixed with $2.5 \%(\mathrm{v} / \mathrm{v})$ glutaraldehyde and $2.0 \%(\mathrm{v} / \mathrm{v})$ paraformaldehyde in $0.1 \mathrm{~mol} / \mathrm{L} \mathrm{PBS}(\mathrm{pH}=7.2)$ at $4{ }^{\circ} \mathrm{C}$ 
overnight, and then washed with PBS three times for 15 min each. The specimens were further fixed with $2 \%$ potassium permanganate $\left(\mathrm{KMnO}_{4}\right)$ for $2 \mathrm{~h}$, washed with PBS three times for 15 min each, dehydrated in a graded acetone series of $30 \%, 50 \%, 70 \%, 85 \%, 95 \%$ and then $100 \%$ for 10 min each, and embedded in Spi-pon-812 resin. Ultrathin sections approximately $60 \mathrm{~nm}$ thick were made by an ultramicrotome (UC-7; Lecia Inc., Wetzslar, Germany) with a diamond knife. Ultra-thin sections were stained with uranyl acetate then lead citrate, and viewed on a TEM (JEL-1400; JEOL Ltd., Tokyo, Japan). As a control, untreated mycelia were also processed for TEM.

\subsection{Impact of Citral on Chitinases of M. grisea}

The chitinase activity of $M$. grisea was measured using a previously published spectrophotometric method [35,36]. First, enzyme liquid extraction was performed by centrifuging $30 \mathrm{~mL}$ of treated mycelial suspension at $6,000 \mathrm{rpm}$ for $15 \mathrm{~min}$ at $4{ }^{\circ} \mathrm{C}$, and discarding the supernatant. The resulting pellet was mixed with approximately $4 \mathrm{~mL}$ of Tris- $\mathrm{HCl}$ buffer $\left(\mathrm{pH}=7.5,4{ }^{\circ} \mathrm{C}\right)$ and ground with a mortar and pestle into a slurry. The slurry was centrifuged at $10,000 \mathrm{rpm}$ for $10 \mathrm{~min}$ at $4{ }^{\circ} \mathrm{C}$. The supernatant was transferred into a $1.5 \mathrm{~mL}$ centrifuge tube and then stored at a low temperature until use. Second, enzyme activity was measured [37]. A solution was made by mixing $0.4 \mathrm{~mL}$ of the colloidal chitin suspension with $0.6 \mathrm{~mL}$ enzyme sample in a test tube, according to previous work by Boller et al. [38], and Nitoda et al. [35]. This solution was placed in a water bath at $37{ }^{\circ} \mathrm{C}$ for $60 \mathrm{~min}$, while stirring with a magnetic stir bar. The solution was then boiled for $5 \mathrm{~min}$ to terminate the reaction, centrifuged at 10,000 rpm for $10 \mathrm{~min}$, and the resulting supernatant was transferred into a $1.5 \mathrm{~mL}$ centrifuge tube. Next, $0.4 \mathrm{~mL}$ of supernatant fluid, $0.2 \mathrm{~mL}$ of $\mathrm{K}_{2} \mathrm{~B}_{4} \mathrm{O}_{7}(0.8 \mathrm{~mol} / \mathrm{L})$, and $3 \mathrm{~mL}$ of $1 \%$ $p$-dimethylaminobenzaldehyde (DMAB) were mixed sequentially. This solution was incubated for $20 \mathrm{~min}$ at $36{ }^{\circ} \mathrm{C}$, and then measured at $544 \mathrm{~nm}$. One unit of enzyme was defined as the change in the amount of $\mathrm{N}$-acetylglucosamine caused by chitinase enzymatic hydrolysis of chitin per hour.

\subsection{Statistical Analysis}

All analyses were performed in four replicates. The data were analyzed using SPSS 12.0 statistical software package (SPSS, Inc., Chicago, IL, USA) and Microsoft Office Excel 2010. Data were first tested for normality and then analyzed by ANOVA. Significant differences between the mean values of each cohort were determined using Duncan's Multiple Range test $(p<0.05)$ following one-way ANOVA.

\section{Conclusions}

In conclusion, citral significantly inhibits the mycelial growth, conidial formation and germination, and appressorium formation of $M$. grisea. The mechanism of action of citral may be capable of causing significant damage to the hyphal cell walls of $M$. grisea, so the antifungal and toxicological characteristics of citral indicate its great potential for agricultural applications in the treatment of fungal pathogen infections, e.g., RBD caused by M. grisea. Further studies on citral, such as in vivo toxicological characteristics, phytotoxicity tests, and field experiments, are required to determine its potential as a commercial fungicide. 


\section{Acknowledgments}

This work was supported by the Special Fund for Agro-Scientific Research of China (No. 20090303308, 201203038-08), by the National Natural Science Foundation of China (No. 21267007), Agricultural Research Projects of the Science and Technology Department of Guizhou Province (No. [2012]3010, [2010]3066), and the Science and Technique Foundation of Guizhou Province (No. [2010]2074).

\section{Author Contributions}

Rong-Yu Li carried out the morphological studies and drafted the manuscript.Xiao-Mao Wu and Xian-Hui Yin participated in the activity study. Jing-nan Liang performed TEM. Ming Li participated in the study conception, design and revised the manuscript for important intellectual content.

\section{Conflicts of Interest}

The authors declare no conflict of interest.

\section{References}

1. Skamnioti, P.; Gurr, S.J. Against the grain: Safeguarding rice from rice blast disease. Trends Biotechnol. 2009, 27, 141-150.

2. Dean, R.A.; Talbot, N.J.; Ebbole, D.J.; Farman, M.L.; Mitchell, T.K.; Orbach, M.J.; Thon, M.; Kulkarni, R.; Xu, J.R.; Pan, H.; et al. The genome sequence of the rice blast fungus Magnaporthe grisea. Nature 2005,434, 980-986.

3. Motallebi, P.; Javan-Nikkhah, M.; Okhovvat, S.M. Characterization of Magnaporthe grisea populations associated with rice and weeds in Iran. Australas. Plant Path. 2013, 42, 693-700.

4. Tani, H.; Koshino, H.; Sakuno, E.; Nakajima, H. Botcinins A, B, C, and D, metabolites produced by Botrytis cinerea, and their antifungal activity against Magnaporthe grisea, a pathogen of rice blast disease. J. Nat. Prod. 2005, 68, 1768-1772.

5. Dean, R.; van Kan, J.A.L.; Pretorius, Z.A.; Hammond-Kosack, K.E.; Pietro, A.D.; Spanu, P.D.; Rudd, J.J.; Dickman, M.; Kahmann, R.; Ellis, J.; et al. The top 10 fungal pathogens in molecular plant pathology. Mol. Plant Path. 2012, 13, 141-430.

6. Zhang, Y.; Li, S.; Jiang, D.; Kong, L.; Zhang, P.; Xu, J. Antifungal activities of metabolites produced by a termite-associated Streptomyces canus BYB02. J. Agric. Food Chem. 2013, 61, 1521-1524.

7. Zhang, C.Q.; Zhou, M.G. Isolation, characterization and preliminary genetic analysis of tricyclazole-resistant mutants of the rice blast fungus, Magnaporthe grisea. J. Phytopathol. 2006, 154, 392-397.

8. Zhang, C.Q.; Huang, X.; Wang, J.X.; Zhou, M.G. Resistance development in rice blast disease caused by Magnaporthe grisea to tricyclazole. Pestic. Biochem. Physiol. 2009, 94, 43-47.

9. Janisiewicz, W.J.; Korsten, L. Biological control of postharvest diseases of fruits. Ann. Rev. Phytopathol. 2002, 40, 411-441. 
10. Haas, D.; Keel, C. Regulation of antibiotic production in root-colonizing Pseudomonas spp. and relevance for biological control of plant disease. Ann. Rev. Phytopathol. 2003, 41, 117-153.

11. Teixeira, R.R.; Pereira, W.L.; Oliveira, A.F.C.; Silva, A.M.; Oliveira, A.S.; Silva, M.L.; Silva, C.C.; Paula, S.O. Natural products as source of potential dengue antivirals. Molecules 2014, 19, 8151-8176.

12. Yoon, M.Y.; Cha, B.; Kim, J.C. Recent trends in studies on botanical fungicides in agriculture. Plant Pathol. J. 2013, 29, 1-9.

13. Wang, Y.; Jiang, Z.T.; Li, R. Complexation and molecular microcapsules of Litsea cubeba essential oil with $\beta$-cyclodextrin and its derivatives. Eur. Food Res. Technol. 2009, 228, 865-873.

14. Wang, H.; Liu, Y. Chemical composition and antibacterial activity of essential oils from different parts of Litsea cubeba. Chem. Biodivers. 2010, 7, 229-235.

15. Liu, T.T.; Yang, T.S. Antimicrobial impact of the components of essential oil of Litsea cubeba from Taiwan and antimicrobial activity of the oil in food systems. Int. J. Food Microbiol. 2012, $156,68-75$.

16. Silva, C.B.; Guterres, S.S.; Weisheimer, V.; Schapoval, E.E.S. Antifungal activity of the Lemongrass oil and citral against Candida spp. Braz. J. Infect. Dis. 2008, 12, 63-66.

17. Saddiq, A.A.; Khayyat, S.A. Chemical and antimicrobial studies of monoterpene: Citral. Pestic. Biochem. Physiol. 2010, 98, 89-93.

18. Aiemsaard, J.; Aiumlamai, S.; Aromdee, C.; Taweechaisupapongc, S.; Khunkitti, W. The effect of lemongrass oil and its major components on clinical isolate mastitis pathogens and their mechanisms of action on Staphylococcus aureus DMST 4745. Res. Vet. Sci. 2011, 91, 31-37.

19. Park, M.J.; Gwak, K.S.; Yang, I.; Kim, K.W.; Jeung, E.B.; Chang, J.W.; Choi, I.G. Effect of citral, eugenol, nerolidol and $\alpha$-terpineol on the ultrastructural changes of Trichophyton mentagrophytes. Fitoterapia 2009, 80, 290-296.

20. Wuryatmo, E.; Klieber, A.; Scott, E.S. Inhibition of citrus postharvest pathogens by vapor of citral and related compounds in culture. J. Agric. Food Chem. 2003, 51, 2637-2640.

21. Ganjewala, D.; Guptam, A.K.; Muhury, R. An update on bioactive potential of a monoterpene aldehyde citral. JBAPN 2012, 2, 186-199.

22. Daferera, D.J.; Ziogas, B.N.; Polissiou, M.G. The effectiveness of plant essential oils on the growth of Botrytis cinerea, Fusarium sp. and Clavibacter michiganensis subsp. Michiganensis. Crop Prot. 2003, 22, 39-44.

23. Roger, A.A.; Thomas, R.H.; David, F.H.; Charles, T.M., Jr.; Randall, W.C.; Pierce, D.F. Structure-antifungal activity relationships among volatile C6 and C9 aliphatic aldehydes, ketones and alcohols. J. Agric. Food Chem. 1994, 4, 1563-1568.

24. Witz, G. Biological interaction of $\alpha, \beta$-unsaturated aldehydes. Free Radic. Biol. Med. 1989, 7 , 333-349.

25. Maoz, M.; Neeman, I. Effect of Inulaviscosa extract on chitin systhesis in dermatophytes and Candida albicans. J. Ethnopharmacol. 2000, 71, 479-482.

26. Xiong, Z.Q.; Tu, X.R.; Wei, S.J.; Li, L.; Huang, X.H.; Lu, H. In vitro antifungal activity of antifungalmycin 702, a new polyene macrolide antibiotic, against the rice blast fungus Magnaporthe grisea. Biotechnol. Lett. 2013, 35, 1475-1479. 
27. Arlorio, M.; Ludwig, A.; Boller, T.; Bonfante, P. Inhibition of fungal growth by plant chitinases and $\beta$-1,3-glucanases. Protoplasma 1992, 171, 34-43.

28. Gooday, G.W.; Zhu, W.Y.; O'Donnell, R.W. What are the roles of chitinases in the growing fungus. FEMS Microbiol. Lett. 1992, 100, 387-392.

29. Abbanat, D.; Leighton, M.; Maiese, W.; Jones, E.B.; Pearce, C.; Greenstein, M. Cell wall active antifungal compounds produced by the marine fungus Hypoxylon oceanicum LL-15G256. I. Taxonomy and fermentation. J. Antibiot. 1998, 51, 296-302.

30. Adams, D.J. Fungal cell wall chitinases and glucanases. Microbiology 2004, 150, 2029-2035.

31. Mauch, F.; Mauch-Mani, B.; Boller, T. Antifungal hydrolases in pea tissue II. Inhibition of fungal growth by combinations of chitinase and $\beta$-1,3-glucanase. Plant Physiol. 1998, 88, 936-942.

32. Sela-Buurlage, M.B.; Ponstein, A.S.; Bres-Vloemans, S.A.; Melchers, L.S.; van den Elzen, P.J.M.; Cornelissen, B.J.C. Only specific tobacco (nicotiana tabacum) chitinases and [ $\beta]-1,3$-glucanases exhibit antifungal activity. Plant Physiol. 1993, 101, 857-863.

33. Bruno, G.B.; Donzelli, G. Interaction of amonium, reducing sugar, and chitin regulates the expression of cell wall degrading enzymes in Trichoderma atroviride strain P1. Appl. Environ. Microbiol. 2001, 67, 5643-5647.

34. Zore, G.B.; Thakre, A.D.; Jadhav, S.; Karuppayil, S.M. Terpenoids inhibit Candida albicans growth by affecting membrane integrity and arrest of cell cycle. Phytomedicine 2011, 18, 1181-1190.

35. Nitoda, T.; Kurumatani, H.; Kanzaki, H.; Kawazu, K. Improved bioassay method for Spodoptera litura chitinase inhibitors using a colloidal chitin powder with a uniform particle size as substrate. Pestic. Sci. 1999, 55, 563-565.

36. Bolar, J.P.; Norelli, J.L.; Harman, G.E.; Brown, S.K.; Aldwinckle, H.S. Synergistic activity of endochitinase and exochitinase from Trichoderma atroviride (T. harzianum) against the pathogenic fungus (Venturia inaequalis) in transgenic apple plants. Transgenic Res. 2001, 10, 533-543.

37. Reissig, J.L.; Strominger, J.L.; Leloir, L.F. A modified colorimetric method for the estimation of N-acetylamino sugars. J. Biol. Chem. 1955, 217, 956-966.

38. Boller, T.; Gehri, A.; Mauch, F.; Vögeli, U. Chitinase in bean leaves: Induction by ethylene, purification, properties, and possible function. Planta 1983, 157, 22-31.

Sample Availability: Samples of the compounds are available (the citral was isolated from Litsea cubeba essential oils) from the authors.

(C) 2014 by the authors; licensee MDPI, Basel, Switzerland. This article is an open access article distributed under the terms and conditions of the Creative Commons Attribution license (http://creativecommons.org/licenses/by/3.0/). 